\title{
Framework for benchmarking online retailing performance using fuzzy AHP and TOPSIS method
}

\author{
Golam Kabir ${ }^{\mathrm{a}^{*}}$ and M. Ahsan Akhtar Hasin ${ }^{\mathrm{b}}$
}

\begin{tabular}{l}
\hline A R T I C L E I N F O \\
\hline Article history: \\
Received 25 October 2011 \\
Received in revised form \\
November, 2, 2011 \\
Accepted March, 52012 \\
Available online \\
7 March 2012 \\
\hline Keywords: \\
Benchmarking \\
Fuzzy AHP \\
On-line retail service providers \\
TOPSIS
\end{tabular}

${ }^{a}$ Department of Civil Engineering, Faculty of Applied Science, The University of British Columbia (UBC), Canada

${ }^{b}$ Department of Industrial and Production Engineering, Bangladesh University of Engineering and Technology (BUET), Dhaka-1000, Bangladesh

\section{Introduction}

The Internet has been evolved from a basic tool of communications into a vast and interactive market of products and services involving over 240 million users worldwide (Guo \& Shao, 2005). The Internet has the potential to market products and services to customers, to communicate information to a global community, to provide an electronic forum for communications and to process business transactions such as orders and payments. Naturally many enterprises across the world attempt to embrace the digital revolution and place a wide range of materials on the web, from infrastructure to databases to actual service online for the convenience of customers. On-line retailing is no longer just an option now but a necessity for enterprises aiming for better performance (Hsieh et al., 2008). This growth in nonstore shopping and new trends in technology have facilitated the introduction of electronic marketing and promise to provide new ways of impacting and serving consumers in the future (Balasubramanian et al., 2002; Sivanad et al., 2004). Traditional retail and consumer business is suffering at a time of unprecedented economic uncertainty. On the other hand, online divisions of retail chains are attracting

\footnotetext{
* Corresponding author.

E-mail: gk.raju@yahoo.com (G. Kabir)

(C) 2012 Growing Science Ltd. All rights reserved.

doi: $10.5267 /$ j. ijiec.2012.03.003
}

\begin{abstract}
Due to increasing penetration of internet connectivity, on-line retail is growing from the pioneer phase to increasing integration within people's lives and companies' normal business practices. In the increasingly competitive environment, on-line retail service providers require systematic and become indispensable to accomplish superior performance to support the on-line retail service providers. This paper uses the fuzzy analytic hierarchy process (FAHP) approach to support a generic on-line retail benchmarking process. Critical success factors for on-line retail service have been identified from a structured questionnaire and literature and prioritized using fuzzy service provider is benchmarked along with four other on-line service providers using TOPSIS method. Based on the benchmark, their relative ranking has also been illustrated.
\end{abstract}


the attention of both consumers looking for a better deal and managers seeking to cut costs (Yoo and Donthu, 2001). To survive in fierce competitive global market, many practitioners and academicians in this field have recently focused on how to improve online service to attract potential customers and on how to retain current customers. E-shop maintenance costs are much lower than those of a traditional retail outlet, as a virtual store saves labor and rental of premises costs. Advantages of the web as a distribution channel have become obvious. In the past year, electronics retail chains have focused on expanding their online retail segment (Fenech \& O’Cass, 2001).

Benchmarking is a quality tool to evaluate products, services, and work processes of organizations that are recognized as representing best practices, for the purpose of organizational improvement (Spendolini, 1992). Benchmarking is most popularly adopted by organizations to understand how well they are performing relative to their competitors. It is also used to identify what management practices are worthwhile to apply in one's own firm in order to achieve desired performance goals. Benchmarking has been defined as "the search for industry best practices that lead to superior performance" (Camp, 1989) but it can also regarded as the constant search for reference points due to the rapid state of change on all fronts (eg. technology, human resources skill, consumer tastes, etc.). The benchmarking process consists of investigating practices and establishing metrics where practices are interpreted as the processes that are employed and metrics are the quantified result of instituting practices (Camp, 1989). Companies have to create close relationships with their upstream and downstream partners due to acute competition. The traditional relationship is no more effective in this competitive era (Bowersox et al., 2000).

Benchmarking is also an industrial research and information gathering process, which enables a manager to compare his or her function's performance to the performance of the same functions in other companies. Many researchers have conducted the comprehensive literature survey on benchmarking for instance Jackson et al. (1994), Zairi and Youssef (1995), Yasin (2002) and more recently by Dattakumar and Jagadeesh (2003). Many benchmarking processes in e-commerce have been reported for instance Ahmed et al. (2006) demonstrated global benchmarking for internet and ecommerce applications and Rickards (2007) evaluated the benchmarking's for the development for an e-commerce in small and medium enterprise. Apart from this, many researchers have also utilized various techniques in benchmarking for instance AHP has been successfully utilised for benchmarking in process performance (Frei \& Harker, 1999), strategic performance (Partovi, 2001), quality performance (Min \& Chung, 2002) and logistics performance of the postal industry (Chan et al., 2006).

This study aimed elucidate the factors that affect success in on-line retail service and then evaluate and rate these factors by analyzing components using the Fuzzy Analytic Hierarchy Process (FAHP) and to benchmark the performance or rank the present case company based on critical success factors among its competitors using Technique for Order Preference by Similarity to Ideal Solution (TOPSIS) method. In the proposed methodology, the AHP with its fuzzy extension, namely fuzzy AHP, is applied to obtain more decisive judgments by substituting membership scales for Saaty's 1-9 scales and weighting them in the presence of vagueness.

There are various fuzzy AHP applications in the literature that propose systematic approaches for selection of alternatives and justification of problem by using fuzzy set theory and hierarchical structure analysis (Anand et al., 2008; Bozbura \& Beskese, 2007; Çakir et al., 2009; Kahraman et al., 2004; Tang \& Beynon, 2005; Xia \& Wu, 2007). Decision makers usually find it more convenient to express interval judgments than fixed value judgments due to the fuzzy nature of the comparison process (Bozdag et al., 2003).

Based on the above premises, the research was undertaken to identify the on-line retail critical success factors, to benchmark the performance of an on-line retail service providers using fuzzy analytic hierarchy process (FAHP) with regard to critical success factors and to rank the present case company 
based on critical success factors among its competitors using technique for order preference by similarity to ideal solution (TOPSIS) method.

The remainder of this paper is organized as follows. Brief note on benchmarking and its implementation for on-line retailing organizations has been described in the next section. After that, we present an overview of the fuzzy set theory, fuzzy AHP technique and TOPSIS method. We then apply this technique in next section to illustrate case study of ORENET, an on-line retail service provider, whose performance has been benchmarked with other on-line retail service providers. Finally, the last section presents the conclusion and discusses the limitations and scope for future work.

\section{Fuzzy Sets Theory and TOPSIS Method}

\subsection{Fuzzy set theory}

Zadeh (1965) came out with the fuzzy set theory to deal with vagueness and uncertainty in decision making in order to enhance precision. Thus the vague data may be represented using fuzzy numbers, which can be further subjected to mathematical operation in fuzzy domain. Thus fuzzy numbers can be represented by its membership grade ranging between 0 and 1. A triangular fuzzy number (TFN) is shown in Figure 1.

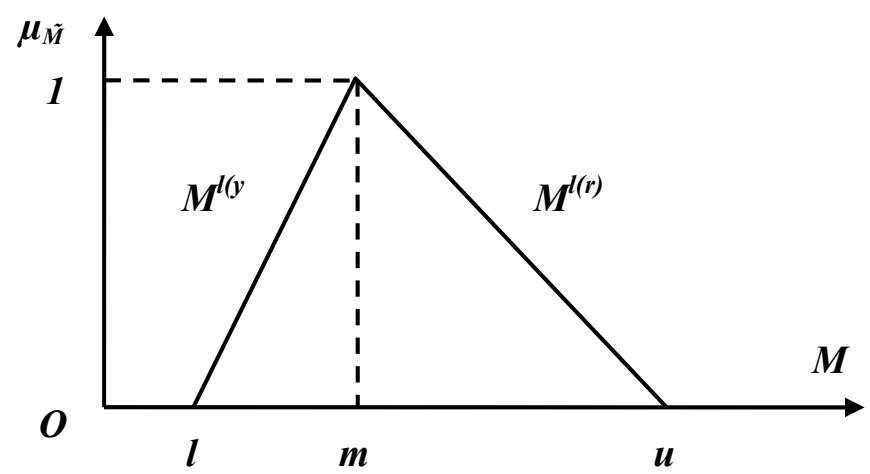

Fig. 1. Triangular Fuzzy Number

A TFN is denoted simply as $(1 / \mathrm{m}, \mathrm{m} / \mathrm{u})$ or $(1, \mathrm{~m}, \mathrm{u})$, represents the smallest possible value, the most promising value and the largest possible value respectively. The TFN having linear representation on left and right side can be defined in terms of its membership function as:

$\mu(x \backslash \tilde{M})=\left\{\begin{array}{cc}0 & x<l \\ (x-l) /(m-l) & l \leq x \leq m \\ (u-x) /(u-m) & m \leq x \leq u \\ 0 & x>u .\end{array}\right.$

A fuzzy number with its corresponding left and right representation of each degree of membership is as below:

$\tilde{M}=\left(M^{l(y)}, M^{l(r)}\right)=(l+(m-l) y, u+(m-u) y), y \in[0,1]$

where $l(y)$ and $l(r)$ denotes the left side representation and the right side representation of a fuzzy number respectively.

The fuzzy summation $\oplus$ and fuzzy subtraction $\Theta$ of any two TFN are also TFNs, but the multiplication $\otimes$ of any two TFNs is only approximate TFNs. The data can be assessed using Table 1, which shows the linguistics scale along with corresponding triangular fuzzy scale. 
Table 1

Linguistic variables describing weights of the criteria and values of ratings

\begin{tabular}{|c|c|c|c|c|}
\hline Linguistic scale for importance & $\begin{array}{l}\text { Fuzzy } \\
\text { numbers }\end{array}$ & Membership function & Domain & $\begin{array}{l}\text { Triangular fuzzy scale } \\
(l, m, u)\end{array}$ \\
\hline Just equal & \multirow{2}{*}{$\tilde{1}$} & & & \multirow{2}{*}{$\begin{array}{l}(1,1,1) \\
(1,1,3)\end{array}$} \\
\hline Equally important & & $\mu_{M}(x)=(3-x) /(3-1)$ & $1 \leq x \leq 3$ & \\
\hline \multirow{2}{*}{ Weakly important } & \multirow{2}{*}{$\tilde{3}$} & $\mu_{M}(x)=(x-1) /(3-1)$ & $1 \leq x \leq 3$ & \multirow{2}{*}{$(1,3,5)$} \\
\hline & & $\mu_{M}(x)=(5-x) /(5-3)$ & $3 \leq x \leq 5$ & \\
\hline \multirow{2}{*}{ Essential or Strongly important } & \multirow{2}{*}{$\tilde{5}$} & $\mu_{M}(x)=(x-3) /(5-3)$ & $3 \leq x \leq 5$ & \multirow{2}{*}{$(3,5,7)$} \\
\hline & & $\mu_{M}(x)=(7-x) /(7-5)$ & $5 \leq x \leq 7$ & \\
\hline \multirow{2}{*}{ Very strongly important } & \multirow{2}{*}{$\tilde{7}$} & $\mu_{M}(x)=(x-5) /(7-5)$ & $5 \leq x \leq 7$ & \multirow{2}{*}{$(5,7,9)$} \\
\hline & & $\mu_{M}(x)=(9-x) /(9-7)$ & $7 \leq x \leq 9$ & \\
\hline Extremely Preferred & $\tilde{9}$ & $\mu_{M}(x)=(x-7) /(9-7)$ & $7 \leq x \leq 9$ & $(7,9,9)$ \\
\hline \multicolumn{3}{|c|}{$\begin{array}{l}\text { If factor } i \text { has one of the above numbers assigned to it when compared to factor } j \text {, } \\
\text { then } j \text { has the reciprocal value when compare to } i\end{array}$} & \multicolumn{2}{|c|}{$\begin{array}{l}\text { Reciprocals of above } \\
M_{1}^{-1}=\left(1 / u_{1}, 1 / m_{1}, 1 / l_{1}\right)\end{array}$} \\
\hline
\end{tabular}

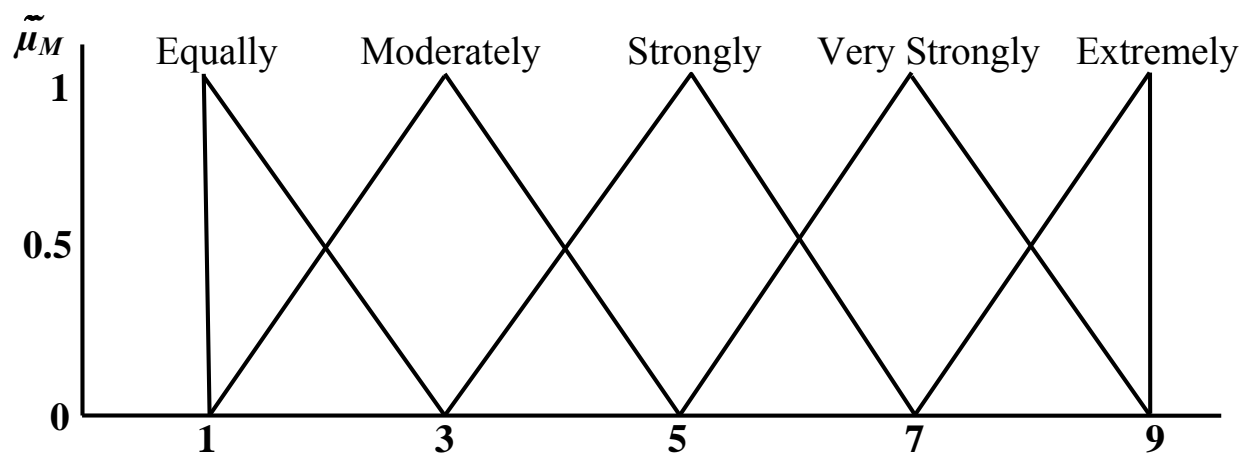

Fig. 2. Linguistic variables for the importance weight of each criterion

If $M_{1}=\left(a_{1}, b_{1}, c_{1}\right)$ and $M_{2}=\left(a_{2}, b_{2}, c_{2}\right)$ are two TFNs, then their operational laws can be expressed as follows:

$\tilde{M}_{1} \oplus \tilde{M}_{2}=a_{1}+a_{2}, b_{1}+b_{2}, c_{1}+c_{2}$

$\tilde{M}_{1} \Theta \tilde{M}_{2}=a_{1}-a_{2}, b_{1}-b_{2}, c_{1}-c_{2}$

$\tilde{M}_{1} \otimes \tilde{M}_{2}=a_{1} \times a_{2}, b_{1} \times b_{2}, c_{1} \times c_{2}$

$\lambda \otimes \tilde{M}_{2}=\lambda \times a_{2}, \lambda \times b_{2}, \lambda \times c_{2}$, where $\lambda>0, \lambda \in R$

$\tilde{M}_{1}^{-1}=\left(1 / c_{1}, 1 / b_{1}, 1 / a_{1}\right)$

\subsection{Fuzzy analytic hierarchy process}

The following section outlines the extent analysis method on FAHP. Let $X=\left\{x_{1}, x_{2}, \ldots, x_{n}\right\}$ be an object set and $U=\left\{u_{1}, u_{2}, \ldots, u_{m}\right\}$ be a goal set. As per Chang $(1992,1996)$ each object is taken and analysis for each goal, $g_{i}$, is performed, respectively. Therefore $m$ extent analysis values for each object can be obtained, as under:

$M_{g_{i}}^{1}, M_{g_{i}, \ldots . .,}^{2} M_{g_{i}}^{m}, \quad i=1,2,3, \ldots . ., \mathrm{n}$

where all the $M_{g_{i}}^{m}(j=1,2, \ldots, \mathrm{m})$ are TFNs whose parameters are, depicting least, most and largest possible values respectively and represented as $(a, b, c)$. 
The steps of Chang's extent analysis (Chang, 1992) can be detailed as follows (Bozbura et al., 2007; Kahraman et al., 2003, 2004, Kabir \& Hasin, 2011a, 2011b):

Step 1: The value of fuzzy synthetic extent with respect to $i$ th object is defined as

$S_{i}=\sum_{j=1}^{m} M_{g_{i}}^{j} \otimes\left[\sum_{i=1}^{n} \sum_{j=1}^{m} M_{g_{i}}^{j}\right]^{-1}$

To obtain $\sum_{j=1}^{m} M_{g_{i}}^{j}$ perform the fuzzy addition operation of $m$ extent analysis values for a particular matrix such that

$\sum_{j=1}^{m} M_{g_{i}}^{j}=\left(\sum_{j=1}^{m} a_{j}, \sum_{j=1}^{m} b_{j}, \sum_{j=1}^{m} c_{j}\right)$

And to obtain $\left[\sum_{i=1}^{n} \sum_{j=1}^{m} M_{g_{i}}^{j}\right]^{\mathbf{- 1}}$ perform the fuzzy addition operation of $M_{g_{i}}^{m}(j=1,2, \ldots, \mathrm{m})$ values such that

$\sum_{i=1}^{n} \sum_{j=1}^{m} M_{g_{i}}^{j}=\left(\sum_{i=1}^{n} a_{i}, \sum_{i=1}^{n} b_{i}, \sum_{i=1}^{n} c_{i}\right)$

And then compute the inverse of the vector in Eq. (11) such that

$\left[\sum_{i=1}^{n} \sum_{j=1}^{m} M_{g_{i}}^{j}\right]^{-1}=\left(\frac{1}{\sum_{i=1}^{n} c_{i}}, \frac{1}{\sum_{i=1}^{n} b_{i}}, \frac{1}{\sum_{i=1}^{n} a_{i}}\right)$

Step 2: The degree of possibility of $M_{2}=\left(a_{2}, b_{2}, c_{2}\right) \geq M_{1}=\left(a_{1}, b_{1}, c_{1}\right)$ is defined as

$V\left(M_{2} \geq M_{1}\right)=\sup \left[\min \left(\mu_{M_{1}}(x), \mu_{M_{2}}(x)\right)\right]$

And can be equivalently expressed as follows:

$V\left(\tilde{M}_{2} \geq \tilde{M}_{1}\right)=\left\{\begin{array}{cl}1 & \text { if } b_{2} \geq b_{1} \\ 0 & \text { if } a_{1} \geq c_{2} \\ \frac{a_{1}-c_{2}}{\left(b_{2}-c_{2}\right)-\left(b_{1}-a_{1}\right)} & \text { otherwise }\end{array}\right.$

where $d$ is the ordinate of the highest intersection point $D$ between $\boldsymbol{\mu}_{\boldsymbol{M}_{\boldsymbol{I}}}$ and $\boldsymbol{\mu}_{\boldsymbol{M}_{\mathbf{2}}}$ as shown in Fig. 3 .

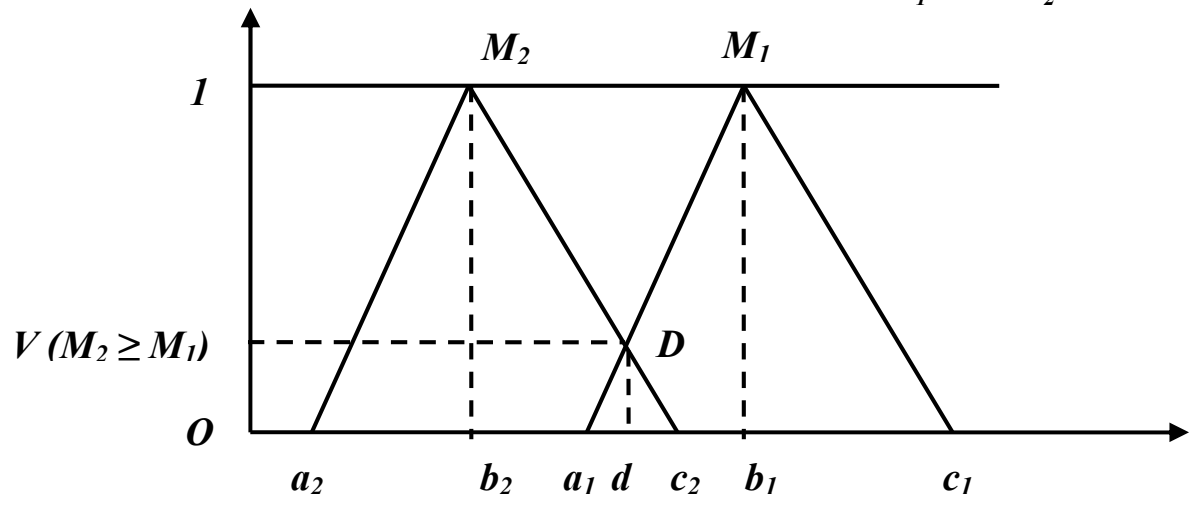

Fig. 3. The intersection between $M_{1}$ and $M_{2}$ 
To compare $M_{1}$ and $M_{2}$, both the values of $V\left(M_{1} \geq M_{2}\right)$ and $V\left(M_{2} \geq M_{1}\right)$.

Step 3: The degree of possibility for a convex fuzzy number to be greater than $k$ convex fuzzy numbers $M_{i}(i=1,2, \ldots . ., k)$ can be defined by

$$
\begin{gathered}
V\left(M \geq M_{1}, M_{2}, \ldots, M_{k}\right)=V\left[\left(M \geq M_{1}\right) \text { and }\left(M \geq M_{2}\right) \text { and } \ldots\left(M \geq M_{k}\right)\right] \\
=\min V\left(M \geq M_{i}\right),(i=1,2,3, \ldots, \mathrm{k}) .
\end{gathered}
$$

Assuming that

$d^{\prime}\left(A_{i}\right)=\min V\left(S_{i} \geq S_{k}\right)$

for $k=1,2,3, \ldots, n ; k \neq i$. Then the weight vector is given by

$W^{\prime}=\left(d^{\prime}\left(A_{1}\right), d^{\prime}\left(A_{2}\right), \ldots \ldots, d^{\prime}\left(A_{n}\right)\right)^{T}$

where $A_{i}=(i=1,2,3, \ldots n)$ are n elements

Step 4: By normalizing, the normalized weight vectors are

$$
W=\left(d\left(A_{1}\right), d\left(A_{2}\right), \ldots \ldots, d\left(A_{n}\right)\right)^{T}
$$

where $W$ is a non-fuzzy number.

\subsection{TOPSIS Method}

TOPSIS (Technique for Order Preference by Similarity to Ideal Solution) is one of the useful Multi Attribute Decision Making techniques that are very simple and easy to implement, so that it is used when the user prefers a simpler weighting approach. On the other hand, the AHP approach provides a decision hierarchy and requires pairwise comparison among criteria. The user needs a more detailed knowledge about the criteria in the decision hierarchy to make informed decisions in using the AHP (Lee et al., 2001). TOPSIS method was firstly proposed by Hwang and Yoon (1981). According to this technique, the best alternative would be the one that is nearest to the positive ideal solution and farthest from the negative ideal solution (Benitez et al., 2007). The positive ideal solution is a solution that maximizes the benefit criteria and minimizes the cost criteria, whereas the negative ideal solution maximizes the cost criteria and minimizes the benefit criteria (Wang and Chang, 2007; Wang and Elhag, 2006; Wang and Lee, 2007; Lin et al., 2008). In other words, the positive ideal solution is composed of all best values attainable of criteria, whereas the negative ideal solution consists of all worst values attainable of criteria (Ertuğrul and Karakasoğlu, 2009). The method is calculated as follows:

Step 1: Construct normalized decision matrix.

This step transforms various attribute dimensions into non-dimensional attributes, which allows comparisons across criteria. Normalize scores or data as follows:

$r_{i j}=x_{i j} /\left(\Sigma x_{i j}^{2}\right)^{1 / 2}$ for $\mathrm{i}=1, \ldots, \mathrm{m} ; \mathrm{j}=1, \ldots, \mathrm{n}$

Step 2: Construct the weighted normalized decision matrix.

Assume we have a set of weights for each criteria $w_{j}$ for $j=1, \ldots, n$. Multiply each column of the normalized decision matrix by its associated weight. An element of the new matrix is:

$v_{i j}=w_{j} r_{i j}$, for $\mathrm{i}=1, \ldots, \mathrm{m} ; \mathrm{j}=1, \ldots, \mathrm{n}$ 
Step 3: Determine the positive ideal and negative ideal solutions.

Positive Ideal solution:

$A^{*}=\left\{v_{1}{ }^{*}, \ldots, v_{n}{ }^{*}\right\}$, where $v_{j}{ }^{*}=\left\{\max \left(v_{i j}\right)\right.$ if $j \in J ; \min \left(v_{i j}\right)$ if $\left.j \in J^{\prime}\right\}$

Negative ideal solution:

$A^{\prime}=\left\{v_{1}{ }^{\prime}, \ldots, v_{n}{ }^{\prime}\right\}$, where $v^{\prime}=\left\{\min \left(v_{i j}\right)\right.$ if $j \in J ; \max \left(v_{i j}\right)$ if $\left.j \in J^{\prime}\right\}$

Step 4: Calculate the separation measures for each alternative.

The separation from the ideal alternative is:

$D_{i}^{*}=\left[\Sigma\left(v_{j}^{*}-v_{i j}\right)^{2}\right]^{1 / 2} \quad \mathrm{i}=1, \ldots, \mathrm{m}$

Similarly, the separation from the negative ideal alternative is:

$D_{i}^{\prime}=\left[\Sigma\left(v_{j}^{\prime}-v_{i j}\right)^{2}\right]^{1 / 2} \quad \mathrm{i}=1, \ldots, \mathrm{m}$

Step 5: Calculate the relative closeness to the ideal solution $\mathrm{CC}_{\mathrm{i}}{ }^{*}$

$C C_{i}^{*}=S_{i}^{\prime} /\left(S_{i}^{*}+S_{i}^{\prime}\right), \quad 0<\mathrm{CC}_{\mathrm{i}}^{*}<1$

Step 6: By comparing $\mathrm{CC}_{\mathrm{i}}{ }^{*}$ values, the ranking of alternatives are determined.

\section{Benchmarking and Its Implementations}

The essence of benchmarking is the process of identifying the highest standards of excellence for products, services or processes and then making the improvements necessary to reach those standards commonly called 'best practices'. Benchmarking in on-line retailing organizations enables the company to constantly monitor and assess its performance and operating techniques against other best of class companies. The process is important to the continuous improvement in an organization's service and expense levels. Benefits from benchmarking for on-line retailing organizations include:

improved market position and sales

$\square$ improved customer satisfaction level

$\boldsymbol{\square}$ identification of information that will enhance and improve throughput and lower expense

$\square$ improved information flow between departments

$\square$ improved customer service and quality control

$\square$ reduced logistics expenses

$\square$ improved team spirit and morale.

Using the benchmarking methodology of Korpela and Tuominen (1996) the revised steps may be listed as follow:

$\square$ define the on-line retail critical factors criteria and sub-criteria

$\square$ identify the companies or alternatives to be included in the analysis

$\square$ analyze performance

aayze the company's situation and identify developmental actions

$\boldsymbol{\square}$ define and implement the improvement plan

$\square$ monitor and update. 


\section{An Empirical Study}

A benchmarking process for performance rating was undertaken for ORENET an on-line retail service provider along with four other on-line retail service providers. A comparison of five existing on-line retail services provider in Bangladesh serves to validate the model by testing the propositions that were developed. To preserve confidentiality, the five on-line retail services provider are referenced as $A_{S}, A_{K}$, $A_{T}, A_{L}$ and $A_{O}($ ORENET) where $\mathrm{S}, \mathrm{K} \mathrm{T}, \mathrm{L}$ and $\mathrm{O}$ indicates the first letter of the respective on-line retail service provider.

A structured undisguised questionnaire was developed containing 34 closed questions and 6 open questions. The questionnaire was sent by e-mail to a convenience sample of about 400 contacts on April 10th 2010, with the invitation to complete the questionnaire for at least one on-line retail service provider. 141 respondents completed the questionnaire, 39 respondents for $A_{S}, 25$ respondents for $A_{K}$, 21 respondents for $A_{T}, 31$ respondents for $A_{L}$ and 25 respondents for $A_{O}$. The main goal of the questionnaire is to identify the success factors or criteria and sub-criteria for on-line retail service provider from the viewpoint of users' perception. In order to evaluate the importance of the critical success factors or criteria and sub-criteria and to analyze the performance of the companies to be benchmarked, the success factors or criteria and sub-criteria are structured into a form of a hierarchy as shown in Figure 4. The Fuzzy AHP model was formulated and data were collected to assess the professional judgment of customers or decision-making executives using the linguistic variables for pair-wise comparisons of criteria and sub-criteria.

A decision matrix ' $\boldsymbol{D}$ ' as shown in Table 2 may be constructed to measure the relative degree of importance for each success factors or criteria, based on the proposed methodology. The decision matrix consist $7 \times 7$ elements.

Table 2

Fuzzy comparison matrix of criteria with respect to the overall objective

\begin{tabular}{cccccccc}
\hline & $C_{1}$ & $C_{2}$ & $C_{3}$ & $C_{4}$ & $C_{5}$ & $C_{6}$ & $C_{7}$ \\
\hline$C_{1}$ & $(1,1,1)$ & $(3,5,7)$ & $(3,5,7)$ & $(1 / 9,1 / 9,1 / 7)$ & $(3,5,7)$ & $(1 / 7,1 / 5,1 / 3)$ & $(1,3,5)$ \\
$C_{2}$ & $(1 / 7,1 / 5,1 / 3)$ & $(1,1,1)$ & $(1 / 5,1 / 3,1)$ & $(1 / 9,1 / 9,1 / 7)$ & $(1 / 5,1 / 3,1)$ & $(1 / 9,1 / 9,1 / 7)$ & $(1 / 7,1 / 5,1 / 3)$ \\
$C_{3}$ & $(1,3,5)$ & $(1 / 7,1 / 5,1 / 3)$ & $(1,1,1)$ & $(1 / 9,1 / 9,1 / 7)$ & $(1 / 3,1,1)$ & $(1 / 9,1 / 9,1 / 7)$ & $(1 / 7,1 / 5,1 / 3)$ \\
$C_{4}$ & $(7,9,9)$ & $(7,9,9)$ & $(7,9,9)$ & $(1,1,1)$ & $(3,5,7)$ & $(1,1,3)$ & $(5,7,9)$ \\
$C_{5}$ & $(1,3,5)$ & $(1 / 7,1 / 5,1 / 3)$ & $(1,1,3)$ & $(1 / 7,1 / 5,1 / 3)$ & $(1,1,1)$ & $(1 / 9,1 / 7,1 / 5)$ & $(1 / 5,1 / 3,1)$ \\
$C_{6}$ & $(7,9,9)$ & $(3,5,7)$ & $(7,9,9)$ & $(1 / 3,1,1)$ & $(5,7,9)$ & $(1,1,1)$ & $(3,5,7)$ \\
$C_{7}$ & $(3,5,7)$ & $(1 / 5,1 / 3,1)$ & $(3,5,7)$ & $(1 / 9,1 / 7,1 / 5)$ & $(1,3,5)$ & $(1 / 7,1 / 5,1 / 3)$ & $(1,1,1)$ \\
\hline
\end{tabular}

Inconsistency of TFN used can be checked and the consistency ratio (CR) may be calculated (Satty, 1998). The results obtained are: $\lambda_{\max }=7.733 ; \mathrm{CI}=0.1221 ; \mathrm{RI}=1.35$ and $\mathrm{CR}=0.0911$. As $\mathrm{CR}<0.1$ the level of inconsistency present in the information stored in ' $\boldsymbol{D}$ ' matrix is satisfactory (Satty, 1998).

$S C_{l}=(11.26,19.31,27.41) \otimes(1 / 161.783,1 / 125.77,1 / 85.4)=(0.07,0.153,0.321)$

$S C_{2}=(1.91,2.28,3.95) \otimes(1 / 161.783,1 / 125.77,1 / 85.4)=(0.011,0.018,0.046)$

$S C_{3}=(2.84,5.62,7.95) \otimes(1 / 161.783,1 / 125.77,1 / 85.4)=(0.018,0.045,0.093)$

$S C_{4}=(31,41,47) \otimes(1 / 161.783,1 / 125.77,1 / 85.4)=(0.191,0.326,0.550)$

$S C_{5}=(3.60,5.88,10.87) \otimes(1 / 161.783,1 / 125.77,1 / 85.4)=(0.022,0.047,0.127)$

$S C_{6}=(26.33,37,43) \otimes(1 / 161.783,1 / 125.77,1 / 85.4)=(0.163,0.294,0.504)$

$S C_{7}=(8.46,14.68,21.53) \otimes(1 / 161.783,1 / 125.77,1 / 85.4)=(0.052,0.117,0.252)$ 


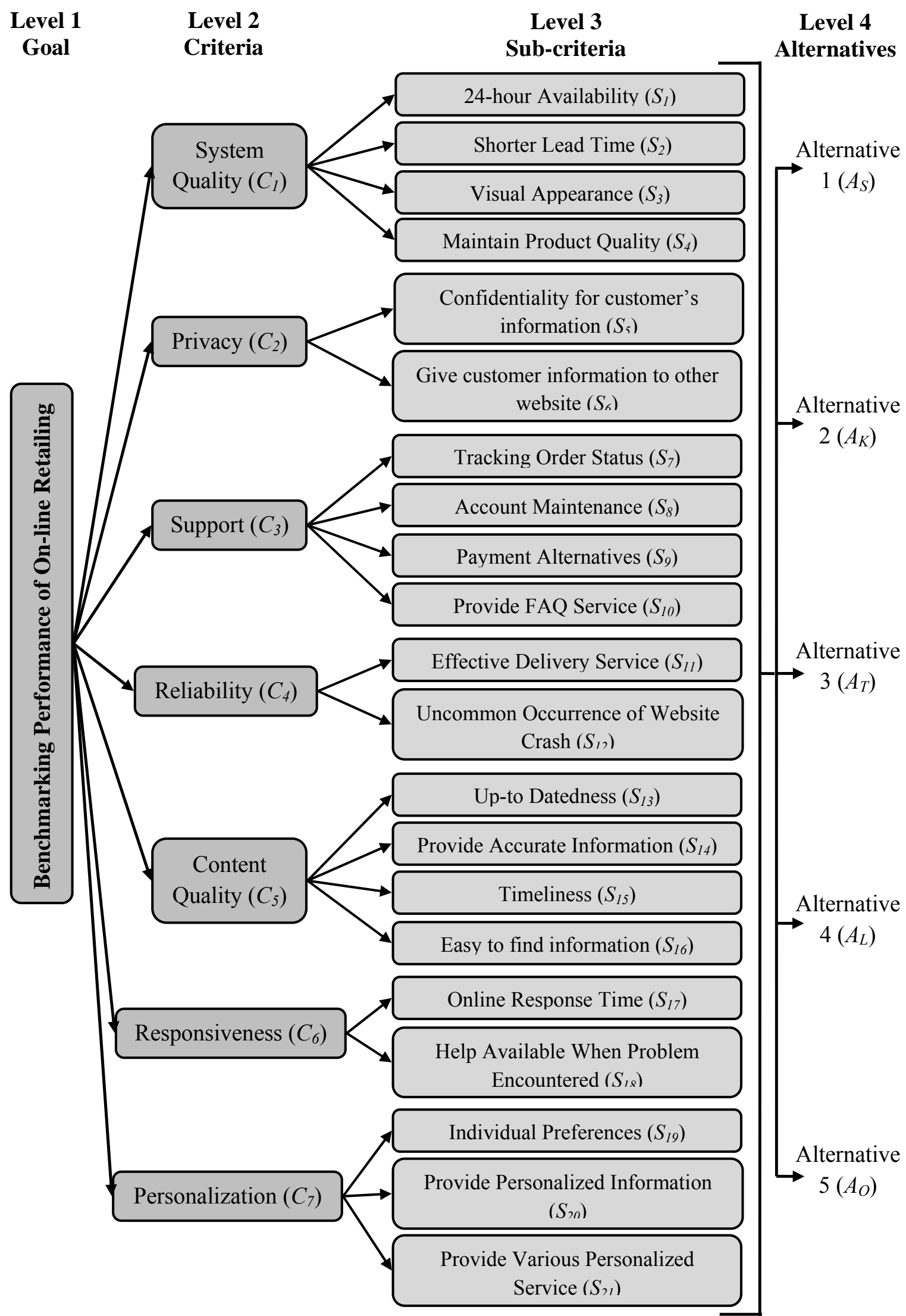

Fig. 4. The objective hierarchy for benchmarking performance of on-line retailing 
The degrees of possibility of superiority of $S C_{l}$ can be calculated by Eqs. (14) and (15) and is denoted by $V\left(S C_{l} \geq S C_{2}\right)$. Therefore, the degree of possibility of superiority for the first requirement- the values are calculated as

$V\left(S C_{1} \geq S C_{2}\right)=1, \quad V\left(S C_{1} \geq S C_{3}\right)=1$,

$V\left(S C_{1} \geq S 4\right)=(0.191-0.321) /(0.153-0.321)-(0.326-0.191)=(-0.13) /(-0.303)=0.43$

$V\left(S C_{1} \geq S C_{2}\right)=1, \quad V\left(S C_{1} \geq S C_{2}\right)=0.528, \quad V\left(S C_{1} \geq S C_{2}\right)=1$

For the second requirement- the values are calculated as

$\begin{array}{lll}V\left(S C_{2} \geq S C_{1}\right)=0.216, & V\left(S C_{2} \geq S C_{3}\right)=0.51, & V\left(S C_{2} \geq S C_{4}\right)=0.89 \\ V\left(S C_{2} \geq S C_{5}\right)=0.453, & V\left(S C_{2} \geq S C_{6}\right)=0.736, & V\left(S C_{2} \geq S C_{7}\right)=0.0645\end{array}$

For the third requirement- the values are calculated as

$V\left(S C_{3} \geq S C_{1}\right)=1, \quad V\left(S C_{3} \geq S C_{2}\right)=0.176, \quad V\left(S C_{3} \geq S C_{4}\right)=0.536$

$V\left(S C_{3} \geq S C_{5}\right)=0.973, \quad V\left(S C_{3} \geq S C_{6}\right)=0.391, \quad V\left(S C_{3} \geq S C_{7}\right)=0.363$

For the fourth requirement- the values are calculated as

$V\left(S C_{4} \geq S C_{1}\right)=1, \quad V\left(S C_{4} \geq S C_{2}\right)=1, \quad V\left(S C_{4} \geq S C_{4}\right)=1$

$V\left(S C_{4} \geq S C_{5}\right)=1, \quad V\left(S C_{4} \geq S C_{6}\right)=1$,

$V\left(S C_{4} \geq S C_{7}\right)=1$

For the fifth requirement- the values are calculated as

$V\left(S C_{5} \geq S C_{1}\right)=1, \quad V\left(S C_{5} \geq S C_{2}\right)=0.35, \quad V\left(S C_{5} \geq S C_{3}\right)=1$

$V\left(S C_{5} \geq S C_{4}\right)=0.303, \quad V\left(S C_{5} \geq S C_{6}\right)=0.171, \quad V\left(S C_{5} \geq S C_{7}\right)=0.517$

For the sixth requirement- the values are calculated as
$V\left(S C_{6} \geq S C_{1}\right)=1, \quad V\left(S C_{6} \geq S C_{2}\right)=1$,
$V\left(S C_{6} \geq S C_{3}\right)=1$

$V\left(S C_{6} \geq S C_{4}\right)=0.907, \quad V\left(S C_{6} \geq S C_{5}\right)=1$,

$V\left(S C_{6} \geq S C_{7}\right)=1$

For the seventh requirement- the values are calculated as
$V\left(S C_{7} \geq S C_{1}\right)=1$,
$V\left(S C_{7} \geq S C_{2}\right)=0.835$,
$V\left(S C_{7} \geq S C_{3}\right)=1$
$V\left(S C_{7} \geq S C_{4}\right)=0.226$,
$V\left(S C_{7} \geq S C_{5}\right)=1$,
$V\left(S C_{7} \geq S C_{6}\right)=0.335$

With the help of Eqs. (16) and (17), the minimum degree of possibility of superiority of each criterion over another is obtained. This further decides the weight vectors of the criteria.

Therefore, the weight vector is given as

$\mathrm{W}^{\prime}=(0.43,0.0645,0.176,1,0.171,0.907,0.226)$

The normalized value of this vector decides the priority weights of each criterion over another. The normalized weight vectors are calculated as

$\mathrm{W}=(0.144,0.022,0.06,0.336,0.056,0.304,0.078)$

The normalized weight of each success factor is depicted in Fig. 5.

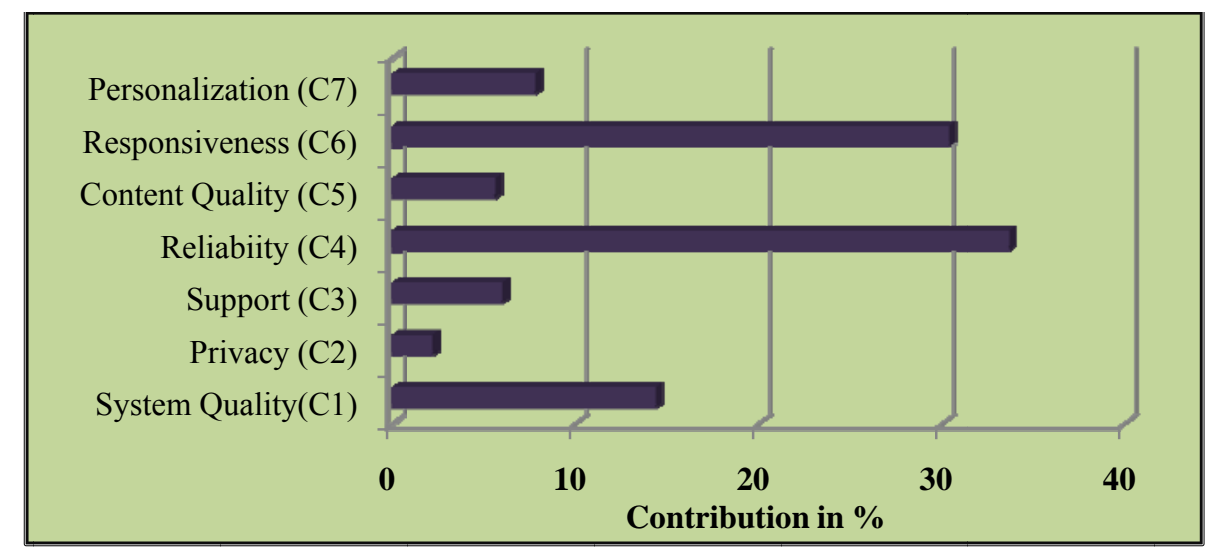

Fig. 5. Contribution of criteria for benchmarking performance of on-line retailing

Figure 5 show that the reliability $\left(C_{4}\right)$ and responsiveness $\left(C_{6}\right)$ have higher priority than the other success factors. As a result, reliability and responsiveness are the essential factors affecting the success of on-line retail service. Now the different sub-criteria are compared under each of the criterion 
separately by following the same procedure discussed above. The fuzzy comparison matrices and the weight vectors of each sub-criterion are shown in Tables 3-9. The priority weight of each sub-criterion has been determined following the similar procedure discussed above.

\section{Table 3}

Fuzzy comparison matrix of the sub-criteria with respect to system quality

\begin{tabular}{llllll}
\hline$C_{1}$ & $S_{I}$ & $S_{2}$ & $S_{3}$ & $S_{4}$ & Weight \\
\hline$S_{1}$ & $(1,1,1)$ & $(1 / 9,1 / 9,1 / 7)$ & $(1 / 3,1,1)$ & $(1 / 7,1 / 5,1 / 3)$ & 0.033 \\
$S_{2}$ & $(7,9,9)$ & $(1,1,1)$ & $(3,5,7)$ & $(1,1,3)$ & 0.55 \\
$S_{3}$ & $(1 / 3,1,1)$ & $(1 / 7,1 / 5,1 / 3)$ & $(1,1,1)$ & $(1 / 5,1 / 3,1)$ & 0.057 \\
$S_{4}$ & $(3,5,7)$ & $(1 / 3,1,1)$ & $(1,3,5)$ & $(1,1,1)$ & 0.36 \\
\hline
\end{tabular}

\section{Table 4}

Fuzzy comparison matrix of the sub-criteria with respect to privacy

\begin{tabular}{llll}
\hline$C_{2}$ & $S_{5}$ & $S_{6}$ & Weight \\
\hline$S_{5}$ & $(1,1,1)$ & $(1,1,3)$ & 0.50 \\
\hline$S_{6}$ & $(1 / 3,1,1)$ & $(1,1,1)$ & 0.50 \\
\hline
\end{tabular}

\section{Table 5}

Fuzzy comparison matrix of the sub-criteria with respect to support

\begin{tabular}{llllll}
\hline$C_{3}$ & $S_{7}$ & $S_{8}$ & $S_{9}$ & $S_{10}$ & Weight \\
\hline$S_{7}$ & $(1,1,1)$ & $(1 / 7,1 / 5,1 / 3)$ & $(1,1,3)$ & $(1 / 3,1,1)$ & 0.157 \\
\hline$S_{8}$ & $(3,5,7)$ & $(1,1,1)$ & $(7,9,9)$ & $(5,7,9)$ & 0.453 \\
\hline$S_{9}$ & $(1 / 3,1,1)$ & $(1 / 9,1 / 9,1 / 7)$ & $(1,1,1)$ & $(1 / 3,1,1)$ & 0.324 \\
\hline$S_{10}$ & $(1,1,3)$ & $(1 / 9,1 / 7,1 / 5)$ & $(1,1,3)$ & $(1,1,1)$ & 0.066 \\
\hline
\end{tabular}

Table 6

Fuzzy comparison matrix of the sub-criteria with respect to reliability

\begin{tabular}{llll}
\hline$C_{4}$ & $S_{11}$ & $S_{12}$ & Weight \\
\hline$S_{I 1}$ & $(1,1,1)$ & $(5,7,9)$ & 0.50 \\
$S_{12}$ & $(1 / 9,1 / 7,1 / 5)$ & $(1,1,1)$ & 0.50 \\
\hline
\end{tabular}

Table 7

Fuzzy comparison matrix of the sub-criteria with respect to content quality

\begin{tabular}{llllll}
\hline$C_{5}$ & $S_{13}$ & $S_{14}$ & $S_{15}$ & $S_{16}$ & Weight \\
\hline$S_{13}$ & $(1,1,1)$ & $(5,7,9)$ & $(3,5,7)$ & $(1,3,5)$ & 0.463 \\
$S_{14}$ & $(1 / 9,1 / 7,1 / 5)$ & $(1,1,1)$ & $(1 / 7,1 / 5,1 / 3)$ & $(1 / 7,1 / 5,1 / 3)$ & 0.006 \\
$S_{15}$ & $(1 / 7,1 / 5,1 / 3)$ & $(3,5,7)$ & $(1,1,1)$ & $(1 / 5,1 / 3,1)$ & 0.21 \\
$S_{16}$ & $(1 / 5,1 / 3,1)$ & $(3,5,7)$ & $(1,3,5)$ & $(1,1,1)$ & 0.321 \\
\hline
\end{tabular}

Table 8

Fuzzy comparison matrix of the sub-criteria with respect to responsiveness

\begin{tabular}{llll}
\hline$C_{6}$ & $S_{17}$ & $S_{18}$ & Weight \\
\hline$S_{17}$ & $(1,1,1)$ & $(1 / 5,1 / 3,1)$ & 0.30 \\
$S_{18}$ & $(1,3,5)$ & $(1,1,1)$ & 0.70 \\
\hline
\end{tabular}

Table 9

Fuzzy comparison matrix of the sub-criteria with respect to personalization

\begin{tabular}{lllll}
\hline$C_{7}$ & $S_{19}$ & $S_{20}$ & $S_{21}$ & Weight \\
\hline$S_{19}$ & $(1,1,1)$ & $(1 / 7,1 / 5,1 / 3)$ & $(1,1,3)$ & 0.086 \\
$S_{20}$ & $(3,5,7)$ & $(1,1,1)$ & $(3,5,7)$ & 0.781 \\
$S_{21}$ & $(1 / 3,1,1)$ & $(1 / 7,1 / 5,1 / 3)$ & $(1,1,1)$ & 0.133 \\
\hline
\end{tabular}

At this stage, the relative priority weights of each criterion and each sub- criterion are calculated. The results of the instance are shown in Table 10 and Fig. 6. 
Table 10

Priority and consistency ratios for benchmarking performance of on-line retailing

\begin{tabular}{|c|c|c|c|c|c|c|}
\hline Criterion & $\begin{array}{l}\text { Priority of } \\
\text { criterion }\end{array}$ & Sub-criterion & $\begin{array}{l}\text { Priority of sub- } \\
\text { criterion }\end{array}$ & $\begin{array}{l}\text { Final priority of } \\
\text { sub-criterion }\end{array}$ & $\begin{array}{l}\text { CR of sub- } \\
\text { criterion }\end{array}$ & $\mathrm{CR}$ of criterion \\
\hline \multirow{4}{*}{$C_{l}$} & \multirow{4}{*}{0.144} & $\overline{S_{I}}$ & 0.033 & 0.0047 & \multirow{4}{*}{0.0478} & \multirow{21}{*}{0.0911} \\
\hline & & $S_{2}$ & 0.55 & 0.0792 & & \\
\hline & & $S_{3}$ & 0.057 & 0.0082 & & \\
\hline & & $S_{4}$ & 0.36 & 0.0518 & & \\
\hline \multirow[b]{2}{*}{$C_{2}$} & \multirow{2}{*}{0.022} & $S_{5}$ & 0.50 & 0.0110 & \multirow{2}{*}{0} & \\
\hline & & $S_{6}$ & 0.50 & 0.0110 & & \\
\hline \multirow{4}{*}{$C_{3}$} & \multirow{4}{*}{0.06} & $S_{7}$ & 0.157 & 0.0094 & \multirow{4}{*}{0.0468} & \\
\hline & & $S_{8}$ & 0.453 & 0.0272 & & \\
\hline & & $S_{9}$ & 0.324 & 0.0194 & & \\
\hline & & $S_{10}$ & 0.066 & 0.0039 & & \\
\hline \multirow{2}{*}{$C_{4}$} & \multirow{2}{*}{0.336} & $S_{11}$ & 0.50 & 0.1680 & \multirow{2}{*}{0} & \\
\hline & & $S_{12}$ & 0.50 & 0.1680 & & \\
\hline \multirow{4}{*}{$C_{5}$} & \multirow{4}{*}{0.056} & $S_{13}$ & 0.463 & 0.0260 & \multirow{4}{*}{0.0716} & \\
\hline & & $S_{14}$ & 0.006 & 0.0003 & & \\
\hline & & $S_{15}$ & 0.21 & 0.0117 & & \\
\hline & & $S_{16}$ & 0.321 & 0.0180 & & \\
\hline \multirow{2}{*}{$C_{6}$} & \multirow{2}{*}{0.304} & $\overline{S_{17}}$ & 0.30 & 0.0912 & \multirow{2}{*}{0} & \\
\hline & & $S_{18}$ & 0.70 & 0.2128 & & \\
\hline \multirow{3}{*}{$C_{7}$} & \multirow{3}{*}{0.078} & $S_{19}$ & 0.086 & 0.0067 & \multirow{3}{*}{0.0497} & \\
\hline & & $S_{20}$ & 0.781 & 0.0609 & & \\
\hline & & $S_{21}$ & 0.133 & 0.1037 & & \\
\hline
\end{tabular}

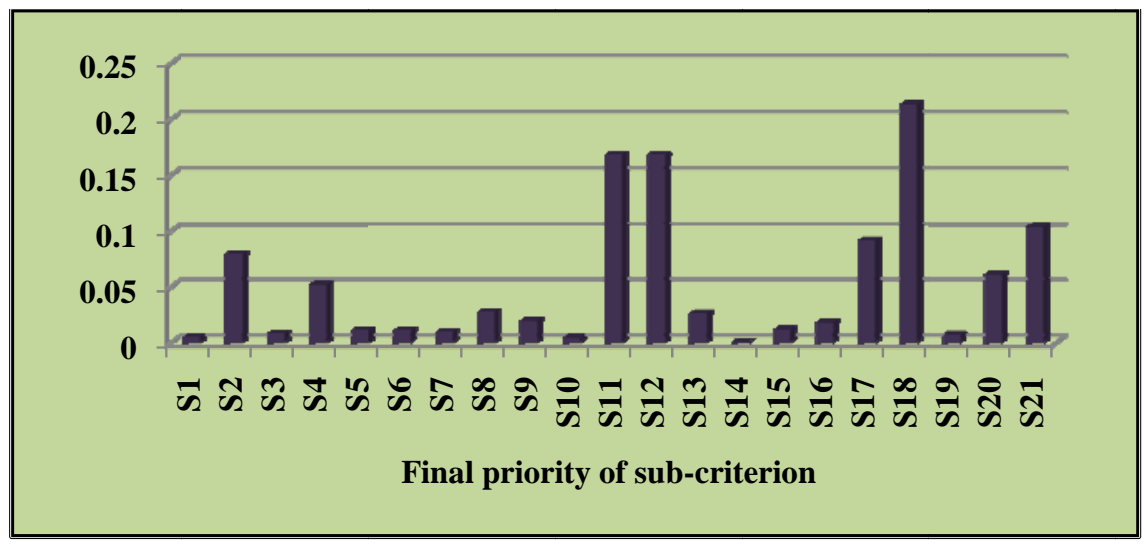

Fig. 6. Importance of sub-criterion for benchmarking performance of on-line retailing

Fig. 6 shows the importance of sub-criteria for benchmarking the performance of on-line retail service providers. Since the consistency of all the level is less than 0.1 , this set of priorities is considered acceptable. The evaluation of the performance of the on-line retail service providers are conducted by a committee of experts that are comprised of five professionals from practice and five from the academia. The performance ratings for the 7 success factors or criteria and 21 sub-criteria with respect to the five alternatives are summarized in Table 11 decision matrix. The decision matrix from Table 11 is used for the TOPSIS analysis. Based on the first step of the TOPSIS procedure, each element is normalized by Eqs. (2). The resulting normalized decision matrix for the TOPSIS analysis is shown in Table 12. Then, weighted normalized matrix is formed by multiplying each value with their corresponding weights. Table 13 shows the normalized weighted decision matrix for each alternative with respect to the each sub-criterion. Positive and negative ideal solutions are determined by taking the maximum and minimum values for each criterion using Eqs. (21) and (22). 
Table 11

Decision matrix for performance evaluation

\begin{tabular}{llllll}
\hline & $A_{S}$ & $A_{K}$ & $A_{T}$ & $A_{L}$ & $A_{O}$ \\
\hline$S_{1}$ & 8 & 7 & 7 & 6 & 8 \\
$S_{2}$ & 6 & 8 & 7 & 5 & 7 \\
$S_{3}$ & 8 & 7 & 6 & 6 & 5 \\
$S_{4}$ & 7 & 5 & 8 & 7 & 6 \\
$S_{5}$ & 8 & 5 & 6 & 7 & 4 \\
$S_{6}$ & 4 & 3 & 5 & 5 & 5 \\
$S_{7}$ & 5 & 6 & 8 & 8 & 6 \\
$S_{8}$ & 7 & 5 & 7 & 7 & 6 \\
$S_{9}$ & 4 & 5 & 4 & 5 & 8 \\
$S_{10}$ & 6 & 7 & 9 & 6 & 7 \\
$S_{11}$ & 6 & 6 & 7 & 5 & 7 \\
$S_{12}$ & 8 & 5 & 6 & 6 & 5 \\
$S_{13}$ & 7 & 8 & 8 & 5 & 6 \\
$S_{14}$ & 9 & 7 & 7 & 7 & 6 \\
$S_{15}$ & 8 & 7 & 7 & 8 & 7 \\
$S_{16}$ & 9 & 9 & 8 & 6 & 8 \\
$S_{17}$ & 6 & 8 & 7 & 7 & 6 \\
\hline$S_{18}$ & 5 & 7 & 6 & 6 & 5 \\
$S_{19}$ & 7 & 8 & 6 & 8 & 5 \\
\hline$S_{20}$ & 6 & 6 & 5 & 6 & 5 \\
$S_{21}$ & 8 & 7 & & & 5 \\
\hline & & & 7 & 5 & \\
\hline
\end{tabular}

Table 12

Normalized decision matrix for TOPSIS analysis

\begin{tabular}{llllll}
\hline & AS & AK & AT & AL & AO \\
\hline$S_{1}$ & 0.2525 & 0.2305 & 0.2206 & 0.2071 & 0.2818 \\
$S_{2}$ & 0.1894 & 0.2635 & 0.2206 & 0.1726 & 0.2466 \\
$S_{3}$ & 0.2525 & 0.2305 & 0.1891 & 0.2071 & 0.1761 \\
$S_{4}$ & 0.2209 & 0.1647 & 0.2521 & 0.2417 & 0.1761 \\
$S_{5}$ & 0.2525 & 0.1647 & 0.1891 & 0.2417 & 0.2113 \\
$S_{6}$ & 0.1262 & 0.0988 & 0.1576 & 0.1726 & 0.1409 \\
$S_{7}$ & 0.1578 & 0.1976 & 0.2521 & 0.2762 & 0.1761 \\
$S_{8}$ & 0.2209 & 0.1647 & 0.2206 & 0.2417 & 0.2113 \\
$S_{9}$ & 0.1262 & 0.1647 & 0.1261 & 0.1726 & 0.2113 \\
$S_{10}$ & 0.1894 & 0.2305 & 0.2836 & 0.2071 & 0.2818 \\
$S_{11}$ & 0.1894 & 0.1976 & 0.2836 & 0.1726 & 0.2466 \\
$S_{12}$ & 0.2525 & 0.1647 & 0.2206 & 0.2071 & 0.2466 \\
$S_{13}$ & 0.2209 & 0.2635 & 0.1891 & 0.1726 & 0.2113 \\
$S_{14}$ & 0.284 & 0.2305 & 0.2521 & 0.2417 & 0.1761 \\
$S_{15}$ & 0.2525 & 0.2305 & 0.2206 & 0.2762 & 0.2113 \\
$S_{16}$ & 0.284 & 0.2964 & 0.2206 & 0.2071 & 0.2113 \\
$S_{17}$ & 0.1894 & 0.2635 & 0.2521 & 0.2417 & 0.2466 \\
\hline$S_{18}$ & 0.1578 & 0.2305 & 0.2206 & 0.2071 & 0.2818 \\
$S_{19}$ & 0.2209 & 0.2635 & 0.1891 & 0.2762 & 0.2113 \\
\hline$S_{20}$ & 0.1894 & 0.1976 & 0.1891 & 0.2071 & 0.1761 \\
$S_{21}$ & 0.2525 & 0.2305 & 0.1576 & 0.1726 & 0.1761 \\
\hline & & & & &
\end{tabular}


Then the distance of each alternative from PIS and NIS with respect to each sub-criterion are calculated with the help of Eqs. (23) and (24). Table 6 shows the separation measure of each alternative form PIS and NIS. The closeness coefficient of each on-line retail service provider is calculated by using Eqs. (25) and the ranking of the alternatives are determined according to these values in Table 13. Finally, the sixth step ranks the alternatives according to Table 13. From Table 13, it is evident that alternative $A_{K}$ demonstrates highest score, hence, must be selected as a potential on-line retail service provider. The order of ranking the alternatives using TOPSIS method results as follows:

$A_{K}>A_{T}>A_{O}>A_{L}>A_{S}$

According to the final scores, we can conclude that the performance of $A_{K}$ provide the best information and service whereas $A_{S}$ demonstrates the least performance from the viewpoint of users' and expert perception. ORENET can improve its performance following the information and services provided by the market leader $\left(A_{K}\right)$ so the best practice can be implemented. In fact, this is a continuous improvement process because the company can improve its weaknesses one by one.

Table 13

TOPSIS analysis results for overall performance of online retail service providers

\begin{tabular}{llllllll}
\hline & $A_{S}$ & $A_{K}$ & $A_{T}$ & $A_{L}$ & $A_{O}$ & $v_{j}{ }^{*}$ & $v_{j}{ }^{-}$ \\
\hline$S_{1}$ & 0.0012 & 0.0011 & 0.001 & 0.001 & 0.0013 & 0.0013 & 0.001 \\
$S_{2}$ & 0.015 & 0.0209 & 0.0175 & 0.0137 & 0.0195 & 0.0209 & 0.0137 \\
$S_{3}$ & 0.0021 & 0.0019 & 0.0016 & 0.0017 & 0.0014 & 0.0021 & 0.0014 \\
$S_{4}$ & 0.0114 & 0.0085 & 0.0131 & 0.0125 & 0.0091 & 0.0131 & 0.0085 \\
$S_{5}$ & 0.0028 & 0.0018 & 0.0021 & 0.0027 & 0.0023 & 0.0028 & 0.0018 \\
\hline$S_{6}$ & 0.0014 & 0.0011 & 0.0017 & 0.0019 & 0.0015 & 0.0011 & 0.0019 \\
$S_{7}$ & 0.0015 & 0.0019 & 0.0024 & 0.0026 & 0.0017 & 0.0026 & 0.0015 \\
$S_{8}$ & 0.006 & 0.0045 & 0.006 & 0.0066 & 0.0057 & 0.0066 & 0.0045 \\
$S_{9}$ & 0.0024 & 0.0032 & 0.0024 & 0.0033 & 0.0041 & 0.0041 & 0.0024 \\
$S_{10}$ & 0.0007 & 0.0009 & 0.0011 & 0.0008 & 0.0011 & 0.0011 & 0.0007 \\
$S_{11}$ & 0.0318 & 0.0332 & 0.0476 & 0.029 & 0.0414 & 0.0476 & 0.029 \\
\hline$S_{12}$ & 0.0424 & 0.0277 & 0.0371 & 0.0348 & 0.0414 & 0.0277 & 0.0424 \\
$S_{13}$ & 0.0057 & 0.0069 & 0.0049 & 0.0045 & 0.0055 & 0.0069 & 0.0045 \\
\hline$S_{14}$ & 0.0009 & 0.0007 & 0.0008 & 0.0007 & 0.0005 & 0.0009 & 0.0005 \\
$S_{15}$ & 0.003 & 0.0027 & 0.0026 & 0.0032 & 0.0025 & 0.0032 & 0.0025 \\
\hline$S_{16}$ & 0.0051 & 0.0053 & 0.004 & 0.0037 & 0.0038 & 0.0053 & 0.0037 \\
$S_{17}$ & 0.0173 & 0.024 & 0.023 & 0.022 & 0.0225 & 0.0173 & 0.024 \\
\hline$S_{18}$ & 0.0336 & 0.0491 & 0.0469 & 0.0441 & 0.06 & 0.06 & 0.0336 \\
\hline$S_{19}$ & 0.0015 & 0.0018 & 0.0013 & 0.0019 & 0.0014 & 0.0019 & 0.0013 \\
\hline$S_{20}$ & 0.0115 & 0.012 & 0.0115 & 0.0126 & 0.0107 & 0.0126 & 0.0107 \\
\hline$S_{21}$ & 0.0262 & 0.0239 & 0.0163 & 0.0179 & 0.0183 & 0.0262 & 0.0163 \\
\hline$S_{i}{ }^{*}$ & 0.0348 & 0.0201 & 0.0204 & 0.0283 & 0.0186 & & \\
\hline$S_{i}{ }^{-}$ & 0.013 & 0.0244 & 0.0243 & 0.0142 & 0.021 & & \\
$C_{i}{ }^{*}$ & 0.272 & 0.5483 & 0.5436 & 0.3341 & 0.5303 & & \\
\hline & & & & & & & \\
\hline
\end{tabular}

\section{Conclusion}

With Internet and Web technologies, online customers can have unlimited access to the information they require and may enjoy a wider range of choices in selecting products and service with highly competitive prices. Therefore, it is generally not easy for online retailers to gain and sustain competitive advantages based solely on a cost leadership strategy in rival-driven online retailing. Rather, the subtle "differentiating" service quality levels of the online retailers have increasingly become a key driving force in enhancing customers' satisfaction and in turn in expanding their customer bases. To survive in fierce competitive global market, many practitioners and academicians in 
this field have recently focused on how to improve online services to attract potential customers and on how to retain current customers. The use of benchmarking is widening in order to support strategic management for survival. Fuzzy AHP may be employed to reduce the vagueness and impreciseness while making judgmental decision to support on-line retail benchmarking process. In the present research, FAHP has been successfully applied to prioritize the critical success factors and TOPSIS method for their subsequent ranking. The various on-line retail service providers have been evaluated with reference to the identified critical success factors for necessary benchmarking. Thus the benchmarking using FAHP has been conducted to achieve the desired performance standard. The benchmarking process helps both users and on-line retail service providers. On-line retail service providers may improve upon their weak area of performance while the users may use the benchmarking process to identify the potential on-line retail service providers and to optimize their requirements. Sampling is a major limitation in this study. Since the survey was conducted based on a sample in Bangladesh, the prudent reader may need to interpret the results of the study with caution, particularly with respect to the generalization of research findings to Bangladesh online customers as a whole. Future research should make several extensions of the current study. Benchmarking process may be further extended by involving the influence of the enablers to on-line retail critical success factors. The enablers may also be ranked in order to find the most vital enabler influencing on-line retail critical success factors, since the benchmarking is a continuous process. Many more companies operating in different sectors can be accommodated in the evaluations. The use of fuzzy ANP (FANP) may be extended to measure the overall impact of enablers.

\section{References}

Ahmed, A.M., Zairi, M., \& Alwabel, S.A. (2006). Global benchmarking for internet and ecommerce applications. Benchmarking: An International Journal, 13(1/2), 68-80.

Anand, D.M., Selvaraj, T., Kumanan, S., \& Johnny, M.A. (2008). Application of multicriteria decision making for selection of robotic system using fuzzy analytic hierarchy process. International Journal of Management and Decision Making, 9(1), 75-98.

Balasubramanian, S., Peterson, R.A., \& Javenpaa, S.L. (2002). Exploring the implications of M-Commerce for markets and marketing. Journal of the Academy of Marketing Science, 30(4), 348-361.

Benitez, J.M., Martin, J.C., \& Roman, C. (2007). Using fuzzy number for measuring quality of service in the hotel industry. Tourism Management, 28(2), 544-555.

Bowersox, D.J., Closs, D.J., Stank, T.P., \& Keller, S.B. (2000). How supply chain competency leads to business success. Supply Chain Management Review, 4(4), 70-77.

Bozbura, F.T., \& Beskese, A. (2007). Prioritization of organizational capital measurement indicators using fuzzy AHP. International Journal of Approximate Reasoning, 44(2), 124-147.

Bozbura, F.T., Beskese, A., \& Kahraman, C. (2007). Prioritization of human capital measurement indicators using fuzzy AHP. Expert Systems with Applications, 3(4), 1100-1112.

Bozdag, C.E., Kahraman, C., \& Ruan, D. (2003). Fuzzy group decision making for selection among computer integrated manufacturing systems. Computers in Industry, 51(1), 13- 29.

Çakir, E., Tozan, H., \& Vayvay, O. (2009). A Method for Selecting Third Party Logistic Service Provider Using Fuzzy AHP. Journal of Naval Science and Engineering, 5(3), 38-54.

Camp, R.C. (1989). Benchmarking: the search for Industry Best practices that Lead to Superior Performance, ASQC Quality Press: Milwaukee.

Chan, F.T.S., Chan, H.K., Lau, H.C.W., \& Ralph, W.L. (2006). An AHP approach in benchmarking logistics performance of the postal industry. Benchmarking: An International Journal, 13(6), 636-661.

Chang, D.Y. (1992). Extent analysis and synthetic decision. Optimization Techniques and Applications, 1, 352355.

Chang, D.Y. (1996). Applications of the extent analysis method on fuzzy AHP. European Journal of Operational Research, 95(3), 649-655.

Dattakumar, R., \& Jagadeesh, R. (2003). A review of literature on benchmarking.Benchmarking: An International Journal, 10(3), 76-209.

Ertuğrul, Đ., \& Karakasoğlu, N. (2009). Performance evaluation of Turkish cement firms with fuzzy analytic hierarchy process and TOPSIS methods. Expert Systems with Applications: An International Journal, 36(1), 702-715. 
Fenech, T., \& O'Cass, A. (2001). Internet users' adoption of Web retailing: user and product dimensions. Journal of Product \& Brand Management, 10(6), 361-81.

Frei, F.X., \& Harker, P.T. (1999). Measuring aggregate process performance using AHP. European Journal of Operational Research, 116(2), 436-442.

Guo, S., \& Shao, B. (2005). Quantitative Evaluation of E-Commercial Websites of Foreign Trade Enterprises in Chongquing. Proceedings of international conference on services systems and services management, June 13-15, 2005, Chongquing, China, 80-785.

Hsieh, C.T., Jones, C., \& Lin, B. (2008). The new business potential with mobile commerce., International Journal of Mobile Communications, 6(4), 436-455

Hwang, C.L., \& Yoon, K. (1981). Multiple attributes decision making methods and applications, Springer, Berlin.

Jackson, A.E., Safford, R.R., \& Swart, W.W. (1994). Roadmap to current benchmarking literature. Journal of Management in Engineering, 10(6), 60-65.

G. Kabir \& M.A.A. Hasin, (2011a). Evaluation of Customer Oriented Success Factors in Mobile Commerce Using Fuzzy AHP. Journal of Industrial Engineering and Management, 4(2), 361-386.

G. Kabir \& M.A.A. Hasin, (2011b). Evaluation of Customer Oriented Success Factors in Mobile Commerce Using Fuzzy AHP, International Journal of Industrial Engineering Computations, Published online first.

Kahraman, C., Cebeci, U., \& Ulukan, Z. (2003). Multi-criteria Supplier Selection Using Fuzzy AHP. Logistics Information Management, 16(6), 382-394.

Kahraman, C., Cebeci, U., \& Ruan, D. (2004). Multi-attribute comparison of catering service companies using fuzzy AHP: the case of Turkey. International Journal of Production Economics, 87(2), 171-184.

Korpela, J., \& Tuominen, M. (1996). Benchmarking logistics performance with an application of the analytic hierarchy process. IEEE Transactions on Engineering Management, 43(3), 323-332.

Lee, W.B., Lau, H., Liu, Z., \& Tam, S. (2001). A fuzzy analytic hierarchy process approach in modular product design. Expert Systems, 18(1), 32-42.

Lin, M.C., Wang, C.C., Chen, M.S., \& Chang C. A. (2008). Using AHP and TOPSIS approaches in customerdriven product design process. Computers in Industry, 59(1), 17-31.

Min, H., \& Chung, K. (2002). Dynamic benchmarking of hotel service quality. Journal of Services Marketing, 16(4), 302-319.

Partovi, F.Y. (2001). An analytic model to quantify strategic service vision. International Journal of Service Industry Management, 12(5), 476-499.

Rickards, R.C. (2007). BSC and benchmark development for an e-commerce SME. Benchmarking: An International Journal, 14(2), 222-250.

Saaty, T.L. (1998). The Analytic Hierarchy Process: Planning, Priority Setting, Resource Allocation, RWS Publications, Pittsburgh, PA.

Sivanad, C., Geeta, M., \& Sulep, M. (2004). Barriers to mobile Internet banking services adoption: an empirical study in Klang Valley of Malaysia. Internet Business Review, 1, 1-17.

Spendolini, M.J. (1992). The Benchmarking Book, American Management Association, New York.

Tang, Y.C., \& Beynon, M.J. (2005). Application and Development of a Fuzzy Analytic Hierarchy Process within a Capital Investment Study. Journal of Economics and Management, 1(2), 207-230.

Wang, T.C., \& Chang, T.H. (2007). Application of TOPSIS in evaluating initial training aircraft under a fuzzy environment. Expert Systems with Applications, 33(4), 870-880.

Wang, Y.J., \& Lee, H.S. (2007). Generalizing TOPSIS for fuzzy multiple-criteria group decision-making. Computers and Mathematics with Applications, 53(11), 1762-1772.

Wang, Y.M., \& Elhag, T.M.S. (2006). Fuzzy TOPSIS method based on alpha level sets with an application to bridge risk assessment. Expert Systems with Applications, 31(2), 309-319.

Xia, W., \& Wu, Z. (2007). Supplier Selection with Multiple Criteria in Volume Discount Environments. Omega, 35, 494-504.

Yasin, M.M. (2002). The theory and practice of benchmarking: then and now. Benchmarking: An International Journal, 9(3), 217-243.

Yoo, B., \& Donthu, N. (2001). Developing a scale to measure the perceived quality of Internet shopping sites (SITEQUAL). Quarterly Journal of Electronic Commerce, 2(1), 31-47.

Zadeh, L.A. (1965). Fuzzy sets. Information and Control, 8, 338-353.

Zairi, M., \& Youssef, M. (1995). A review of key publications on benchmarking: part I.Benchmarking for Quality Management and Technology, 2(1), 65-72. 